\title{
A Comparative Study of Haemodynamic Changes and Blood Sugar Levels Before and After Induction of General Anaesthesia With Thiopentone and Propofol"
}

Authors

\section{Dr. Priyanka Gotluru ${ }^{1}$, Dr. Pratibha Kumari², Dr. Ramu Valluri ${ }^{3}$}

${ }^{1}$ Senoir Resident, Dept of Anaesthesiology, Kamineni Academy of Medical Sciences and Research Centre, LB Nagar, Hyderabad, Telangana state,

${ }^{2}$ Assistant Professor, Dept of Anaesthesiology, Kamineni Academy of Medical Sciences And Research Centre, LB Nagar, Hyderabad, Telangana state, India

${ }^{3}$ Professor and HOD, Dept of Anaesthesiology, Kamineni Academy of Medical Sciences And Research Centre, LB Nagar, Hyderabad, Telangana state, India.

Corresponding Author

\section{Dr. Priyanka Gotluru}

Senoir Resident, Dept of Anaesthesiology, Kamineni Academy of Medical Sciences and Research Centre, LB Nagar, Hyderabad, Telangana state,

Email: dr.priyanka.kamsrchyd@gmail.com

Abstract
In this study a total of 100 patients of ASA I \& II undergoing elective surgery under general
anaesthesia were randomized in two groups comprising 50 patients each. An informed written consent
was obtained from all the patients. This study is conducted at Kamineni Academy of Medical sciences and
research centre,Hyderabad. Among the two groups, the first group (Group T) all the patients were
induced with Inj. Thiopentone $5 \mathrm{mg} / \mathrm{kg}$ body weight IV and second (Group P) patients were induced with
Inj. Propofol 5mg/kg body weight IV respectively. There after random blood sugar (RBS) was recorded 5
min before induction (5 min BI). Before induction base line vital parameters were recorded; including
blood pressure and heart rate. The demographic data was comparable in two groups. The
results of our study showed that Propofol significantly reduced PR, SBP, DBP, MAP, and RPP after
induction and 1,3,5,10 min after endotracheal intubation as compared to Thiopentone. Systolic blood
pressure and diastolic arterial blood pressure and mean arterial pressure were below the baseline or near
the baseline in propofol group after induction and intubation while in thiopentone group, all the values
were above the baseline after induction. Heart rate was above the baseline after induction in thiopentone
group while it was below the baseline in propofol group. Thus Propofol provides stable hemodynamic
condition during induction, laryngoscopy and endotracheal intubation when compared to thiopentone.


RBS was measured in both groups at base line and 5 minutes after induction in both the groups it was significantly reduced in propofol group.

Keywords: Anaesthesia, thiopentone, propofol, haemodynamic changes, random blood sugars.

\section{Introduction}

An Ideal inducing Agent for general Anaesthesia Should have hemodynamic stability, Minimal respiratory side effects and rapid clearance. The concerns for induction of anaesthesia in patients undergoing cardiacsurgery include hemodynamic stability, attenuation of stress response and maintenance of balance between myocardial oxygen demand and supply. Various Intravenous anaesthetic agents like Thiopentone, Etomidate, Propofol ,Midazolam, and Ketamine have been used for anesthetizing patients for cardiac surgeries.

The introduction of thiopental in to clinical practice in 1934 represents one of the most significant advances in the development of Anaesthesiology. Thiopentone sodium is a derivative of barbituric acid it is the sulphur anologue of pentobarbitone agent. Thiopentone has been the faster induction agent of anaesthesia because of it's rapid action. The main draw-back are increased incidence of laryngospasm, bronchospasm allergic reaction, decrease in arterial blood pressure. Due to it's cardiorespiratory depressive effects thiopentone is not the drug of choice in shocked patients ${ }^{1}$.

Propofol is the most frequently used IV anesthetic today. Propofol anaesthesia has satisfactory recovery, short half-life, rapid elimination from the blood circulation, causing less sedative effect and vomiting are the reasons for using this drug more commonly [2] This is a short-acting intravenous anesthetic, which is used for induction of anaesthesia in patients older than three years and inducing and maintaining anaesthesia in adult patients. The most important side-effects of this drug are hypotension \& bradycardia by increasing the production and release of nitric oxide[3]. In a study conducted in past on 25000 patients, it was shown that propofol would lead to bradycardia in $4.2 \%$ of patients [4]. Inducing anaesthesia with propofol $(2-2.5 \mathrm{mg} / \mathrm{kg})$ could lower blood pressure as much as $25-40 \%$ in all the patients regardless of any underlying conditions [5]. Propofol caused hypotension is due to the reduction of preload and after load of heart, which are not synchronized with heart's compensatory responses and would be intensified by high doses and high speed injection of the drug [6].

Present study is a comparative study of haemodynamic changes and blood sugar levels before and after induction of general anaesthesia with thiopentone sodium and propofol in elective patients induced under general anaesthetic management.

\section{Materials \& methods}

After having approval from the institutional scientific and ethics committee, prospective randomized clinical study on 100patients, with 50 patients in each group.i.e.Group $\mathrm{T}$ (Thiopentone) and Group P (Propofol). The study was undertaken at OT complex in Kamineni Academy of Medical sciences and Research Institute, Hyderabad during November 2015 to October 2017 i.e.two years. Patients those were included in the study were age 15 to 45 years of both sex, ASA grade I and II, not known allergic to mentioned anaesthetic drugs, non diabetic patient, haemodynamically stable patients. Exclusion criteria was patient not fulfilling inclusion criteria, lack of patient consent, hypothyroid and hyperthyroid patients, heart block and active disease of CNS were excluded.

In order to randomize computer generated randomization table was used. Among the two groups, the first group (Group T) treated with inj Thiopentone sodium and second (Group P) patients were treated with Inj.Propofol .All the patients underwent a thorough pre-anaesthetic checkup and investigated for all the routine and special investigations as per hospital protocol. Study was carried out after getting informed written consent from the patient. 
All patients were premedicated with I.M glycopyrrolate $0.2 \mathrm{mg}$ half an hour before induction. After receiving the patient in Operation Theater (OT), an intravenous line (IV) was secured with IV cannula and Normal Saline drip was started. Thereafter random blood sugar (RBS) recorded $5 \mathrm{~min}$ before induction $(5 \mathrm{~min}$ BI).Before induction base line vital parameters were recorded; including blood pressure and pulse rate.

In the OT patient received IV midazolam 0.03 $\mathrm{mg} / \mathrm{kg}$ and IV fentanyl $2 \mathrm{mcg} / \mathrm{kg}$ five minutes before induction, and was preoxygenated with $100 \%$ oxygen. Then patient was induced with IV propofol at the dose of $2.0 \mathrm{mg} / \mathrm{kg}$ body weight as a induction agent $<15 \mathrm{sec}$ in group $\mathrm{P}$ and thiopentone IV $5 \mathrm{mg} / \mathrm{kg}$ body weight for Group T respectively using peripheral cannula, until the patient's verbal response was lost. Then IV succinylcholine $1.5 \mathrm{mg} / \mathrm{kg}$ was used as muscle relaxant in both the groups and intubation was done after IPPV, connected to work station and continued with nitrous oxide and oxygen mixture (70:30) and inhalational agent was used to maintain the anaesthesia. After 5 mins of induction, patients blood sugar was recorded in both the groups. Later on as soon as intermediate muscle relaxant was administered i.e. injection atracurium $0.5 \mathrm{mg} / \mathrm{kg}$ and continued.

Simultaneously patient's haemodynamic - SBP, DBP, MAP and HR were recorded at $1 \mathrm{~min}, 2$ $\mathrm{min}, 3 \mathrm{~min}, 5 \mathrm{~min}$ and $10 \mathrm{~min}$ after induction. The patients hemodynamic indicators such as systolic blood pressure (SBP), diastolic blood pressure (DBP), mean arterial pressure (MAP), heart rate (HR)were recorded before induction(T1), $1 \mathrm{~min}$ (T2), $2 \min (\mathrm{T} 3), \quad 3 \min (\mathrm{T} 4), \quad 5 \min (\mathrm{T} 5)$ and $10 \mathrm{~min}(\mathrm{~T} 6)$ after Induction. Hypertension was defined as increase in SBP $>20 \%$, Hypotension $<20 \%$ of baseline, tachycardia as HR $>20 \%$ and bradycardia is defined as $<60 / \mathrm{min}$ of baseline recordings.

\section{Statistical Analysis}

All statistical analyses was performed using the SPSS version 18.0 (SPSS Inc., chicago ,IL, USE ).
Quantitative data was presented as means and standard deviation (mean \pm sd) and qualitative data as frequency and $95 \%$ confidence interval (CI).Age, weight and sex will be analyzed using frequencies test. Systolic, diastolic and mean arterial pressure, as well as heart rate was analysed using unpair student's t test and analysed with chi-2 or student's t test. Significance defined as $\mathrm{p}<0.05$

\section{Results}

This In this study a total of 100 patients undergoing elective surgery under general anaesthesia were randomized in two groups comprising 50 patients each. In order to randomize computer generated randomization table was used. Among the two groups, the first group (Group T) all the patients were induced with Inj. Thiopentone and second (Group P) patients were induced with Inj. Propofol.

The demographic data was comparable in both groups.

Table 1: Age Wise Distribution among Two groups

\begin{tabular}{|c|c|c|c|}
\hline Age in years & $\mathrm{T}(\mathrm{No})$ & $\mathrm{P}((\mathrm{No})$ & Total$((\mathrm{No})$ \\
\hline$<20$ & 4 & 5 & 9 \\
\hline $20-29$ & 14 & 17 & 31 \\
\hline $30-39$ & 14 & 10 & 24 \\
\hline$>40$ & 18 & 18 & 36 \\
\hline Total & 50 & 50 & 100 \\
\hline
\end{tabular}

The above table and shows age wise distribution among the two groups, the mean age for group $\mathrm{P}$ was 33.00 years and group $\mathrm{T}$ was 32.52years. There were 24 female and 26 male patients in group $\mathrm{T}$ and 21 female and 29 male patients in group $\mathrm{P}$. The difference among groups was statistically insignificant. P value was 0.24 . The mean weight in group $\mathrm{P}$ was $55.29 \pm 5.69$ and group $\mathrm{T}$ was $58.23 \pm 9.65$ and both weights were comparable.The haemodynamic parameters like systolic blood pressure, diastolic blood pressure, mean arterial blood pressure and heart rate were shown in table 2,3,4,5 respectively. 
Table 2: Systolic blood pressure [SBP]

\begin{tabular}{|c|c|c|}
\hline $\begin{array}{c}\text { SBP at different time } \\
\text { interval }\end{array}$ & $\mathrm{T}(\mathrm{mm}$ of $\mathrm{Hg})$ & $\mathrm{P}(\mathrm{mm}$ of $\mathrm{Hg})$ \\
\hline $\mathrm{T} 1$ & $109.9 \pm 8.6$ & $111.3 \pm 7.5$ \\
\hline $\mathrm{T} 2$ & $107.4 \pm 11.6$ & $95.1 \pm 7.8^{*}$ \\
\hline $\mathrm{T} 3$ & $123.2 \pm 12.6$ & $110.8 \pm 10.2$ \\
\hline $\mathrm{T} 4$ & $115.5 \pm 10.6$ & $105.1 \pm 11.2$ \\
\hline $\mathrm{T} 5$ & $109.5 \pm 11.3$ & $100.7 \pm 10.3$ \\
\hline T6 & $105.7 \pm 11.1$ & $97.5 \pm 11.3$ \\
\hline
\end{tabular}

The above table shows the mean of the systolic blood pressure of the two groups, there was statistically significant difference regarding blood pressure between two groups. There was fall in SBP after induction (T2) and increase in blood pressure (T3) in propofol group.

Table 3: Diastolic Blood Pressure [DBP] Monitoring

\begin{tabular}{|c|c|c|}
\hline DBP at different times & $\mathrm{T}(\mathrm{mm}$ of $\mathrm{Hg})$ & $\mathrm{P}(\mathrm{mm}$ of $\mathrm{Hg})$ \\
\hline $\mathrm{T} 1$ & $66.7 \pm 6.9$ & $69.1 \pm 6.3$ \\
\hline $\mathrm{T} 2$ & $62.7 \pm 6.7$ & $59.9 \pm 5.6$ \\
\hline $\mathrm{T} 3$ & $78.4 \pm 10.9$ & $68.9 \pm 7.5$ \\
\hline T4 & $71.5 \pm 11.2$ & $64.3 \pm 6.8$ \\
\hline T5 & $66.7 \pm 10.3$ & $60.8 \pm 7.0$ \\
\hline T6 & $63.5 \pm 9.1$ & $58.3 \pm 7.1$ \\
\hline
\end{tabular}

The above table and graph shows that there is statistically significant difference among two groups regarding DBP.

Table 4: Mean Arterial Pressure [MAP]

Monitoring

\begin{tabular}{|c|c|c|}
\hline $\begin{array}{c}\text { MAP at different } \\
\text { time interval }\end{array}$ & $\mathrm{T}(\mathrm{mm}$ of $\mathrm{Hg})$ & $\mathrm{P}(\mathrm{mm}$ of $\mathrm{Hg})$ \\
\hline $\mathrm{T} 1$ & $80.6 \pm 7.0$ & $82.5 \pm 6.4$ \\
\hline T2 & $76.8 \pm 7.8$ & $71.0 \pm 5.8$ \\
\hline T3 & $92.7 \pm 10.5$ & $82.0 \pm 8.2$ \\
\hline T4 & $85.3 \pm 8.9$ & $77.5 \pm 7.3$ \\
\hline T5 & $78.7 \pm 13.1$ & $73.5 \pm 6.6$ \\
\hline T6 & $77.3 \pm 8.6$ & $70.6 \pm 7.1$ \\
\hline
\end{tabular}

The above table and graph shows the mean arterial blood pressure groups, the difference among the groups was statistically significant.

The below table shows the HR changes among two groups, there was a statistically significant difference in HR after induction
Table 5: Heart Rate [HR] Monitoring

\begin{tabular}{|c|c|c|}
\hline $\begin{array}{c}\text { HR beats per } \\
\text { min }\end{array}$ & T $($ Mean $\pm \mathrm{sd})$ & $\mathrm{P}($ Mean $\pm \mathrm{sd})$ \\
\hline $\mathrm{T} 1$ & $83.9 \pm 10.4$ & $83.0 \pm 12.3$ \\
\hline $\mathrm{T} 2$ & $81.0 \pm 11.1$ & $76.8 \pm 13.1$ \\
\hline $\mathrm{T} 3$ & $96.6 \pm 11.1$ & $90.5 \pm 15.1$ \\
\hline $\mathrm{T} 4$ & $90.5 \pm 13.25$ & $83.3 \pm 12.57$ \\
\hline $\mathrm{T} 5$ & $84.6 \pm 12.23$ & $77.3 \pm 11.4$ \\
\hline $\mathrm{T} 6$ & $80.2 \pm 11.36$ & $72.7 \pm 11.3$ \\
\hline
\end{tabular}

Table 6: RBS Monitoring in Propofol Group \& Paired t Test Results

\begin{tabular}{|c|c|c|}
\hline Group & $\begin{array}{c}\text { Rbs 5 Mins. Before } \\
\text { Induction }\end{array}$ & $\begin{array}{c}\text { Rbs 5 Mins. } \\
\text { After Induction }\end{array}$ \\
\hline $\mathrm{T}$ & $96.88 \pm 10.48$ & $95.32 \pm 11.05$ \\
\hline $\mathrm{P}$ & $98.98 \pm 9.92$ & $93.04 \pm 7.72^{*}$ \\
\hline
\end{tabular}

Random Blood Sugars was measured in both groups at base line and 5 minutes after induction in both the groups it was significantly reduced in propofol group.

\section{Discussion}

An ideal intravenous induction agent should produce minimal disturbance of cardiovascular and respiratory functions, should induce sleep in one arm brain circulation time, should chemically be stable, non-inflammable, nontoxic, easy to administer.

The present study compared the efficacy of inj. Thiopentone and inj. Propofol for controlling cardiovascular responses. The results of our study showed that Propofol significantly reduced PR, SBP, DBP, MAP, and RPP after induction and $1,3,5,10 \mathrm{~min}$ after endotracheal intubation as compared to Thiopentone.

Propofol is presumed to exert its sedativehypnotic effects through an interaction with gamma-amino butyric acid (GABA) receptor complex. The major cardiovascular effect of propofol is a decrease in arterial blood pressure owing to drop in systemic vascular resistance, cardiac contractility and preload. Hypotension is more pronounced with thiopental but is usually reversed by the stimulation accompanied laryngoscopy and intubation. Factors exacerbating the hypotension include large doses, rapid injection and old age [7]. Propofol markedly 
impairs the normal arterial baroreceptor reflex response to hypotension particularly in conditions of normocarbia or hypocarbia. Rarely, a marked drop in preload may lead to vagally mediated reflex bradycardia. Changes in heart rate and cardiac output are usually transient and insignificant in healthy patients but may be severe enough to lead to a systole particularly in patients at extremes of age, on negative chronotropic medication, or undergoing surgical procedures associated with the oculocardiac reflex[8].

Patients with impaired cardiac function may experience a significant drop in cardiac output as a result of decrease in ventricular filling pressure and contractility. Although myocardial oxygen consumption and coronary blood flow decrease to a similar extent, coronary sinus lactate production increase in some patients. This indicates a regional mismatch between myocardial oxygen supply and demand[9] Induction is occasionally accompanied by excitatory phenomen on such as muscle twitching, spontaneous movements, opisthotonus, or hiccups possibly due to subcortical glycine antagonism. Although these reactions may occasionally mimic tonic-clonic seizures, propofol appears to have predominant anticonvulsant properties[10].

N. Mackenzie and I.S. Grant [11] compared the new emulsion formulations of di-isopropyl phenol (Propofol) with methohexitone and thiopentone for induction of anaesthesia in 60 patients of ASA (American Society of Anaesthesiologist) I or II, undergoing minor urological surgery as a day care surgery. They observed that mean decrease in SBP in the propofol group was $30 \mathrm{~mm} \mathrm{Hg}$ compared with $18 \mathrm{~mm} \mathrm{Hg}$ in the other groups and concluded that propofol caused more marked decreases in SBP in the first 2 minutes after induction.

G. Rolly and L. Versichelen[12] studied three groups of patients posted for gynecological surgery receiving either $1.5 \mathrm{mg} / \mathrm{kg}$ or $2 \mathrm{mg} / \mathrm{kg}$ Propofol or $4 \mathrm{mg} / \mathrm{kg}$ Thiopentone. They found significant increase in PR, SBP and DBP after 1 minute of induction in thiopentone as compared to propofol group. PR, SBP and DBP increased significantly from the baseline value in thiopentone group but decreased significantly to baseline values in propofol group 2 minutes after induction. Pain was not reported during or after the injection.

Leonora T. Fahy et al [13] showed that Thiopentone caused little fall in SBP, DBP and MAP while propofol caused a greater decrease, which at 3 minutes after induction caused decrease by mean of over 30 and $20 \mathrm{~mm} \mathrm{Hg}$ respectively. Fall in diastolic pressure were evident upto 4-6 minutes after injection in propofol group..

F. Boer, J. G. Bovill, P. Ros, H. Van Ommen [14] studied the effect of thiopentone, etomidate and propofol on systemic vascular resistance (SVR) during cardiopulmonary bypass with constant pump flow undergoing elective coronary artery bypass surgery. SVR decreased to $78 \%$ of control values after thiopentone $4 \mathrm{mg} / \mathrm{kg}$, to $72 \%$ of control after etomidate $0.3 \mathrm{mg} / \mathrm{kg}$, and to $68 \%$ of control after propofol $2 \mathrm{mg} / \mathrm{kg}$; it returned to control values $10 \mathrm{~min}$ after administration of propofol.

In the study of Hug et al [14] that was conducted on 25000 patients showed that Propofol would lead to bradycardia in $4.2 \%$ of patients and hypotension in $15.7 \%$ of patients. Bradycardia was reported in one patient $(2.00 \%)$ in our study belonging to propofol group but was statistically not significant.

Jack et al [16] conducted a study on to know cardiovascular changes after achieving constant effect-site concentration of propofol. Propofol TCI was started with a target of $8 \mu \mathrm{g} / \mathrm{mL}$ and then reduced to $4 \mu \mathrm{g} / \mathrm{mL}$ after 2 minutes. They observed a fall in heart rate by $21 \%$, cardiac index by $14 \%$, mean arterial pressure by $28 \%$ due to vasodilatation.In our study also we observed fall in heart rate and MAP in propofol group.

$S$ Behdad et al[17], studied effects of propofol and isoflurane on blood glucose levels for abdominal hysterectomy in diabetic patients. They concluded that propofol prevent increasing in blood glucose during the surgery in comparison to isoflurane anesthesia. In our study also blood glucose level 
decreased in propofol group ${ }^{[98] .}$ However studies done by Oztekin et al [18] studied the changes in lipids, glucose and plasma osmolality during propofol or midazolam infusion during and in early postoperative period following surgery. They observed a significant increase in triglycerides and very low-density lipoprotein levels $4 \mathrm{hr}$ postoperatively in propofol group. Changes in glucose levels did not differ significantly different between the two groups. In patients with normal serum lipids, glucose, and plasma osmolality undergoing $\mathrm{CABG}$, propofol infusion for maintenance anaesthesia is not associated with dangerous changes in serum lipids, glucose, and plasma osmolality compared with midazolam. A propofol infusion technique for maintenance of anesthesia for cardiac surgery where serum lipids and glucose may be of concern could be recommended as an alternative to midazolam. In our study in the group in $\mathrm{P}$, randomm blood sugars was a statically significantly reduced after induction.

\section{Conclusion}

Systolic blood pressure, diastolic arterial blood pressure and mean arterial pressure were below the baseline or near the baseline in propofol group after induction and intubation while in thiopentone group, all the values were above the baseline after induction. Heart rate was above the baseline after induction in thiopentone group while it was below the baseline in propofol group. After intubation, pulse rate increased in both the groups. Thus Propofol provides stable hemodynamic condition during induction, laryngoscopy and endotracheal intubation when compared to thiopentone.

\section{Acknowledgement:}

Authors acknowledge the immense help received from Kamineni Academy of Medical sciences and Research center, the scholars whose articles are cited and included in references of this manuscript. The authors are also grateful to authors/editors/publishers of all those articles, journals and books from where the literature for this article has been reviewed and discussed.

\section{References}

1. David Caro, Ron M Walls, Jonathan Grayzel. sedation or induction agents for rapid Sequence intubation In Adults. AMJ Emergen Medicine May 2011; 17: 141, 19.2

2. Duke T. A new intravenous anesthetic agent: propofol. The Canadian Veterinary Journal. 1995 Mar;36(3):181.

3. Riznyk L, Fijałkowska M, Przesmycki K. Effects of thiopental and propofol on heart rate variability during fentanyl-based induction of general anesthesia. Pharmacol Rep. 2005 57:128-34.

4. Hug CC, Jr, McLeskey $\mathrm{CH}$, Nahrwold ML, Roizen MF, Stanley TH, Thisted RA, et al.Hemodynamic effects of propofol: Data from over 25,000 patients. Anesth Analg. 1993; 77:S21-9.

5. Hiller SC, Mazurek MS. Monitored anesthesia care. In: Barash PG, Cullen BF, Stoelting RK, editors.Clinical Anesthesia. 5th ed. Philadelphia: Lippincott Williams and Wilkins; 2006. pp. 1246-61.

6. Schmidt C, Roosens C, Struys M, Deryck YL, Van Nooten G, Colardyn F,et al.Contractility in humans after coronary artery surgery Anesthesiology. 1999; 91:58-70.

7. Larsen R, Rathgeber J, Bagdahn A, et al: Effects of propofol on cardiovascular dynamics and coronary blood flow in geriatric patients: A comparison with etomidate. Anaesthesia 1988; 43(Suppl):25-31.

8. Stephan H, Sonntag H, Schenk HD, et al: Effects of propofol on cardiovascular dynamics, myocardial blood flow and myocardial metabolism in patients with coronary artery disease. $\mathrm{Br} \mathrm{J}$ Anaesth 1986; 58:969-975.

9. Wahr JA, Plunkett JJ, Ramsay JG, et al: Cardiovascular responses during sedation 
after coronary revascularization: Incidence of myocardial ischemia and hemodynamic episodes with propofol versus midazolam. Institutions of the McSPI Research Group. Anesthesiology 1996; 84:1350-1360.

10. Aun CS, Short SM, Leung DH, Oh TE: Induction dose-response of propofol in unpremedicated children. $\mathrm{Br} \mathrm{J}$ Anaesth 1992; 68:64-67.

11. Mackenzie and Grant. Comparison of the new emulsion formulation of Propofol with Methohexitione and Thiopentone for Induction of Anaesthesia in day cases. Br J Anaesth. 1985; 57:725-31.

12. G. Rolly, and L. Versichelen.Comparison of propofol and thiopentone for induction of anaesthesia in premecated patients. Anaesthesia.1985; 40:945-48.

13. Leonora T. Fahy, G. A. Van Mourik and J. E. Utting. A comparison of the induction characteristics of thiopentone and propofol (2, 6-di-isopropy phenol). Anaesthesia. 1985; 40:939-44

14. Boer F, Bovill JG, Ros P, Van Ommen H. Effect of Thiopentone Etomidate And Propofol on Systemic Vascular Rascular Resistance During Cardio Pulmonary By Pass. British Journal of Anaesthesia 1991; 67(1): 69-72.

15. Hug CC, Jr, McLeskey CH, Nahrwold ML, Roizen MF, Stanley TH, Thisted RA, et al.Hemodynamic effects of propofol: Data from over 25,000 patients. Anesth Analg. 1993; 77:S21-9.

16. Jack ES, Shaw M, Harten JM, et al. Cardiovascular changes after achieving constant effect site concentration of propofol. Anaesthesia 2008;63(2):116120.

17. S Behdad, Mortazavizadeh A, Ayatollahi $\mathrm{V}$, Khadiv $\mathrm{Z}$ and $\mathrm{n}$ Khalilzadeh $\mathrm{S}$. Anesthetic techniques for pharyngeal flap surgery: effects on postoperative complications. Arch Otolaryngol Head Neck Surg. 2002; 128(1):35-9
18. Oztekin I, Gokdogan S, Oztekin DS, Işsever H, Goksel O, Canik S. Effects of propofol and midazolam on lipids, glucose, and plasma osmolality during and in the early postoperative period following coronary artery bypass graft surgery: a randomized trial. Yakugaku Zasshi. 2007; 127(1):173-82. 